\title{
SIMPSON'S PARADOX
}

\section{AN EXAMPLE USING ACCIDENT DATA FROM THE STATE OF TEXAS}

\author{
KeITH SMITh and JAMES O'DAY \\ University of Michigan, Highway Safety Research Institute, Ann Arbor, MI 48109, U.S.A.
}

(Received 4 August 1980)

\begin{abstract}
Two-way tabulation of data when a third interacting variable is present can lead to false inferences. In this paper it is shown that the probability of an occupant fatality given a crash in a single-vehicle accident is independent of vehicle size in an aggregate data set. When the data set is partitioned into 2 occupant age groups, it is seen that both of the age groups have higher fatality rates in smaller cars. This is discussed as an example of a paradox presented by Simpson in his 1951 paper.
\end{abstract}

Numerous analyses have assessed the relative safety of larger and smaller passenger cars. Analyses that have considered both single-vehicle and 2-vehicle accidents have shown that occupants of a smaller car are at a decided disadvantage in 2-vehicle collisions [O'Neill et al., 1974 and Preston, 1975]. However, their disadvantage in single-vehicle accidents is not so well documented. This paper discusses an analysis conducted to compare the fatality rates for drivers in single-car accidents, as a function of both the car weight and the age of the driver.

Available data for the State of Texas allow identification of vehicle size or weight (by grouping "like" cars), as well as identification of the accident class and other factors. We have taken data for single-vehicle passenger car crashes from Texas for a 2-yr period (1975-76), using the census of fatal accidents and a $5 \%$ sample of all reported crashes as inputs to the analysis.

Passenger cars are identified in the Texas files generally by the model name under which the vehicle is sold-1973 Ford LTD., 1974 Chevrolet Impala, etc. This "make" identification information has been recoded into $(500 \mathrm{lb})$ weight classes by reference to published curb weights. Both the accident frequency (from the sample file) and the fatality frequency (from the fatal census) have then been tabulated by weight class. The initial tabulation is shown in Table 1 .

Overall the odds against a single-car accident resulting in death to the driver are estimated at $76: 1$. When log odds is regressed against weight of the vehicle, these odds are estimated to decrease by $11 \%$ for every $1000 \mathrm{lb}$ of vehicle weight. This estimate is only marginally significant $(p=0.04$ ) but is quite consistent across the range of weights in this study. In equation form, this is:

$$
\log _{e} O=+3.967+1.035 \times 10^{-4} W
$$

where $\log _{e} O$ is the natural logarithm of the odds against a fatality, and $W$ is the weight of the vehicle in pounds (computed at the midpoint of the class).

Table 1. Accidents and fatalities by car weight class single vehicle accidents (Texas-1975-76)

\begin{tabular}{|c|c|c|c|}
\hline $\begin{array}{c}\text { Car Weight } \\
\text { Class }\end{array}$ & $\begin{array}{c}\text { Total Crashes } \\
\text { (5t Sample) }\end{array}$ & $\begin{array}{c}\text { Driver } \\
\text { Fatalities }\end{array}$ & $\begin{array}{c}\text { Fatality } \\
\text { Rate }\end{array}$ \\
\hline 1500-2499 & 608 & 191 & .0156 \\
\hline 2500-2999 ib & 710 & 191 & .0130 \\
\hline $3000-34991 b$ & 882 & 222 & .0125 \\
\hline $3500-39992 b$ & 1542 & 412 & .0133 \\
\hline $4000+1 b$ & 1056 & 248 & .0117 \\
\hline
\end{tabular}


One factor in the accident data which interacts strongly with vehicle weight is driver age. At least in the time period of this data, young drivers were much more likely to be in smaller cars, and older drivers in larger cars. This relationship interacts with the probability of fatality computation, in part because older persons are more likely to die (than are young persons) in a given crash situation. To study this effect, the data were divided into 2 driver age groups. The results are shown in Table 2.

When the data are separated by age group, the 2 fatality rates (by car size and age group) may be seen in the last 2 columns of Table 2 . It is clear that for older persons there is a strong relationship of fatality rate with car size-they are about 1.5 times less likely to die, given a crash, in a $4000+\mathrm{lb}$ car as in a $1500-2499 \mathrm{lb}$ car. Further the progression with weight is relatively linear for this group.

The odds against a young driver being killed in a single car accident are estimated to be $84: 1$, while for the older drivers the overall odds are $55: 1$, for the distribution of driver-vehicle weight frequencies in these data. When log odds are regressed separately for each age-group, we estimate that each $1000 \mathrm{lb}$ of vehicle weight reduces the odds of fatality for the young drivers by $14 \%$ and for the older drivers by $26 \%$. Both weight effects are highly significant $(<0.01)$ and both are larger than was observed when driver age was ignored. Again these effects were consistent across the range of vehicle weights observed in these data, but somewhat less so for young than for old drivers. The odds of an older driver being killed in the smallest vehicle weight class are $86 \%$ higher than for younger drivers, and $47 \%$ higher in the largest weight class.

Regression similar to the one shown above for the aggregate data were computed for the age sub-groups, and are as follows:

$$
\begin{aligned}
& \log _{\text {eAGE }=35+}=+3.178+2.326 \times 10^{-4} \mathrm{~W} \\
& \log _{\text {eAGE }=<35}=+4.012+1.269 \times 10^{-4} \mathrm{~W}
\end{aligned}
$$

where $\log _{e}$ and $W$ have the same meanings as above.

The computed data points are shown in Fig. 1, along with the three regression lines. As we noted above, each of the subsets (old and young) exhibits a larger slope than does the aggregate. One might be tempted to conclude from the aggregate that car size has very little effect on the probability of fatality for single-vehicle crashes. But this is clearly not so for persons over $35 \mathrm{yr}$ of age, and even persons younger than 35 show a modest increase in the odds against a fatality with increasing car size.

The kind of variation shown here between the aggregated and disaggregated data is often identified as a demonstration of Simpson's[1951] paradox. Indeed, disaggregation of experimental data can change the results in any of several directions. In this particular case, the aggregate data seem to mask a real effect-an effect that is more important for older persons than for young.

An important inference from this analysis is that there is a relatively strong relationship of the probability of fatality with car size for older persons. With the current trend toward smaller cars, the driver age/car size relationship is bound to change-so that we will be seeing many

\begin{tabular}{|c|c|c|c|c|c|c|}
\hline \multirow{2}{*}{$\begin{array}{c}\text { Car } \\
\text { Weight } \\
\text { class }\end{array}$} & \multicolumn{2}{|c|}{ Total Crashes (5: Sample) } & \multicolumn{2}{|c|}{ Driver Fatalities } & \multicolumn{2}{|c|}{ Fatality Rate } \\
\hline & $\begin{array}{c}\text { Driver } \\
<35 \text { years }\end{array}$ & $\begin{array}{c}\text { Driver } \\
35+\text { years }\end{array}$ & $\begin{array}{l}\text { Driver } \\
<35 \text { years }\end{array}$ & $\begin{array}{l}\text { Driver } \\
35+\text { years }\end{array}$ & $\begin{array}{c}\text { Driver } \\
<35 \text { years }\end{array}$ & $\begin{array}{l}\text { Driver } \\
35+\text { years }\end{array}$ \\
\hline $1500-2499 \mathrm{lb}$ & 533 & 75 & 158 & 33 & .0148 & .0220 \\
\hline $2500-2999 \mathrm{lb}$ & 575 & 135 & 129 & 62 & .0112 & .0229 \\
\hline $3000-34991 b$ & 752 & 130 & 169 & 53 & .0112 & .0203 \\
\hline $3500-3999 \mathrm{Lb}$ & 1167 & 375 & 278 & 134 & .0119 & .0179 \\
\hline $4000+1 b$ & 652 & 404 & 132 & 116 & .0101 & .0143 \\
\hline
\end{tabular}

Table 2. Accidents and fatalities by driver age group single vehicle crashes (Texas-1975-76) 


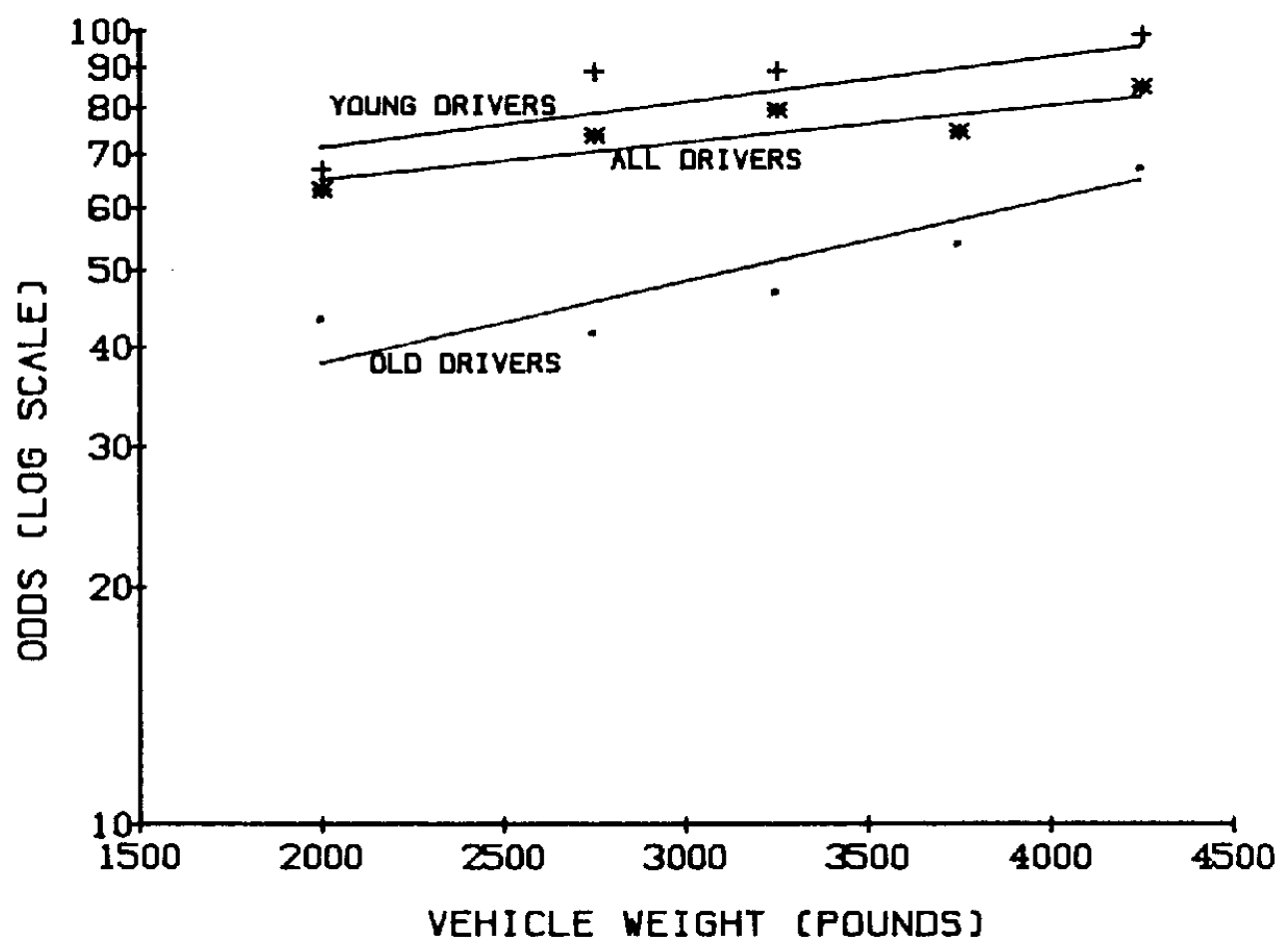

Fig. 1.

more older drivers in smaller cars. Given the aggregate result of this analysis, we might conclude that single-vehicle crashes will produce no more fatalities in the future than in the past; but the disaggregated data would suggest that this is not so. Indeed, if all older drivers were to change to the smallest weight class of this study, other things being equal we would expect the odds against fatality for them to drop from the current 55:1 to 38:1. Put another way one would expect an increase of more than $40 \%$ in the number of fatalities (in singlevehicle crashes) amongst drivers over the age of 35 . The same computation for the younger drivers yields a predicted increase of $17 \%$, while ignoring age, the predicted increase is only $10.5 \%$.

Many other factors, of course, may interact with those presented here. This analysis did not look at restraint usage, crash severity (e.g. as measured by Delta- $V$ ), accident types, etc. These other factors may also be important to such a prediction, and a more comprehensive analysis would certainly be in order. The principal purpose of this paper is to demonstrate that Simpson's paradox is real, and that it is dangerous to draw conclusions from the first correlation one finds.

\section{REFERENCES}

O'Neill B., Joksch H. and Haddon W., Jr., Relationships between car size, weight, and crash injuries in car-to-car crashes. In Proc. 3rd Int. Cong. Auto Safety. Washington, D.C. 1974.

Preston F., Interactions of occupant age, vehicle weight and the probability of dying in a two-vehicle crash. Hit. Lab. Reports 5(12), 1-8, 1975.

Simpson E. H., The interpretation of interaction in contingency tables. J. Roy. Stat. Soc. B13, 238-241, 1951. 